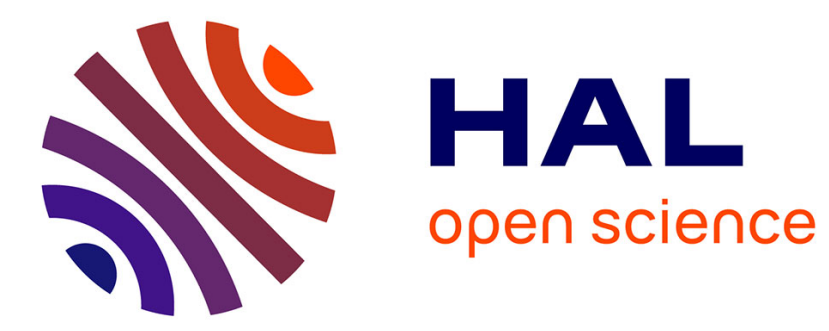

\title{
Effects of seat parameters and sitters' anthropometric dimensions on seat profile and optimal compressed seat pan surface
}

Xuguang Wang, Michelle Cardoso, Georges Beurier

\section{- To cite this version:}

Xuguang Wang, Michelle Cardoso, Georges Beurier. Effects of seat parameters and sitters' anthropometric dimensions on seat profile and optimal compressed seat pan surface. Applied Ergonomics, 2018, 73, pp. 13-21. 10.1016/j.apergo.2018.05.015 . hal-02123154

\section{HAL Id: hal-02123154 \\ https://hal.science/hal-02123154}

Submitted on 7 May 2019

HAL is a multi-disciplinary open access archive for the deposit and dissemination of scientific research documents, whether they are published or not. The documents may come from teaching and research institutions in France or abroad, or from public or private research centers.
L'archive ouverte pluridisciplinaire HAL, est destinée au dépôt et à la diffusion de documents scientifiques de niveau recherche, publiés ou non, émanant des établissements d'enseignement et de recherche français ou étrangers, des laboratoires publics ou privés. 
Post-print : WANG, Xuguang, CARDOSO, Michelle, BEURIER, Georges, 2018, Effects of seat parameters and sitters' anthropometric dimensions on seat profile and optimal compressed seat pan surface, Applied Ergonomics, 73, Elsevier, pp. 13-21, DOI: https://doi.org/10.1016/j.apergo.2018.05.015

$2^{\text {nd }}$ Revision

\section{A parametric investigation on seat/occupant contact forces and their relationship with initially perceived discomfort using a configurable seat}

Xuguang Wang ${ }^{\mathrm{a}, \mathrm{b}, \mathrm{c}^{*}}$, Michelle Cardoso ${ }^{\mathrm{a}, \mathrm{b}, \mathrm{c}}$, Ilias Theodorakos ${ }^{\mathrm{a}, \mathrm{b}, \mathrm{c}}$, Georges Beurier ${ }^{\mathrm{a}, \mathrm{b}, \mathrm{c}}$

${ }^{a}$ Université de Lyon, F-69622, Lyon, France

${ }^{b}$ Université Claude Bernard Lyon 1, Villeurbanne

'IFSTTAR, UMR_T9406, LBMC Laboratoire de Biomécanique et mécanique des chocs, F69675,Bron;

Total words :4245

- Introduction : 490

- $\quad$ Materials and Methods: 1043

- $\quad$ Results : 1023

- $\quad$ Discussion : 1568

- $\quad$ Conclusion : 121

* Corresponding author: Xuguang Wang, LBMC-Ifsttar, 25 av. F. Mitterrand, case 24, 69675 BRON Cedex, France

Tel: +33 (0)4.72.14.24.51

Fax: +33 (0)4.72.14.23.60

Email: xuguang.wang@ifsttar.fr 
Post-print : WANG, Xuguang, CARDOSO, Michelle, BEURIER, Georges, 2018, Effects of seat parameters and sitters' anthropometric dimensions on seat profile and optimal compressed seat pan surface, Applied Ergonomics, 73, Elsevier, pp. 13-21, DOI: https://doi.org/10.1016/j.apergo.2018.05.015

\section{Abstract ( $<150$ words)}

The present work investigates the contact forces between sitters and seat as well as their correlations with perceived discomfort. Twelve different economy class airplane seat configurations were simulated using a multi-adjustable experimental seat by varying seat pan and backrest angles as well as seat pan compressed surface. 18 males and 18 females, selected by their body mass index and stature, tested these configurations for two sitting postures. Perceived discomfort was significantly affected by seat parameters and posture, and correlated both with normal force distribution on the seat-pan surface and with normal forces at the lumbar and head supports. Lower discomfort ratings were obtained for more evenly distributed normal forces on the seat pan. Shear force at the seat pan surface was at its lowest when sitters were allowed to self-select their seat-pan angle, supporting that a shear force should be reduced but not zeroed to improve seating comfort.

\section{Keywords}

Seat; Comfort; Discomfort; Contact force distribution; Airplane

\section{Practitioner Summary ( $<\mathbf{5 0}$ words)}

The effects of seat-pan and backrest angle, anthropometric dimensions and sitting posture on contact forces and perceived discomfort were investigated using a multi-adjustable experimental seat. In addition to preferred seat profile parameters, the present work provides quantitative guidelines on contact force requirement for improving seating comfort. 
Post-print : WANG, Xuguang, CARDOSO, Michelle, BEURIER, Georges, 2018, Effects of seat parameters and sitters' anthropometric dimensions on seat profile and optimal compressed seat pan surface, Applied Ergonomics, 73, Elsevier, pp. 13-21, DOI: https://doi.org/10.1016/j.apergo.2018.05.015

\section{Introduction}

Despite the many studies on sitting comfort, limited research is available on how contact forces are distributed over different seat support surfaces and on how they interact with seat parameters, sitters' anthropometry and posture. As a hyperstatic system, the seated human body with multiple contact surfaces can be supported with more than one combination of contact forces. A change in sitting posture or in muscle activation can lead to a different distribution of contact forces. The contact force distribution pattern, which may be related to perceived sitting discomfort, could provide insights into how sitting posture is controlled. As pressure mapping systems are relatively cheap and easily applicable, they are one of the objective methods most commonly used to analyze and to compare different seats or sitting positions (Zemp et al., 2015). De Looze et al. (2003) concluded from a review of 21 studies that pressure measurements on the seat-pan and back-rest surfaces could be considered the objective variables most closely related to subjective ratings. Mergl et al. (2005) attempted to determine ideal pressure distribution on the seat-pan surface. More recently, Jones et al. (2017) tried to predict effects of seat and sitter dimensions on pressure distribution. Research was also performed on sensitivity to pressure variation on the ischial tuberosity (Goossens et al., 2005a) and on the middle of the thigh (Hartung et al., 2004), and on differences in pressure sensitivity for body-seat contact areas (Vink and Lips, 2017). Although contact pressures are dependent on support forces, pressure mats only measure normal force at the contact surface. However, shear force is also generally suggested as an important factor affecting seating discomfort and pressure-sore risk (Goossens et al., 1994; Zhang et al., 1993). Bush and Hubbard (2007) were among the very few investigators to study support forces in different seated driving positions for midsized males. Both normal and shear forces were found to be significantly affected by seat-back inclination or torso-articulation change. Apart from exploring a potential relationship between subjective perception and pressure distribution, few investigations have addressed possible relationships with other seat support forces.

Most existing studies on seating comfort used a real seat or an experimental seat affording little opportunity to vary design parameters (see the review by Hiemstra-van Mastrig et al., 2017). It is therefore difficult to isolate the effects of one particular seat parameter and to look at its interaction with other variables. To understand the effect of shear force and to develop quantitative guidance regarding seat design, recently we built a multi-adjustable experimental seat equipped with force sensors to measure all contact forces. Within a collaborative research program developing future airline seats, the experimental seat was used to investigate the effects 
Post-print : WANG, Xuguang, CARDOSO, Michelle, BEURIER, Georges, 2018, Effects of seat parameters and sitters' anthropometric dimensions on seat profile and optimal compressed seat pan surface, Applied Ergonomics, 73, Elsevier, pp. 13-21, DOI: https://doi.org/10.1016/j.apergo.2018.05.015

of sitter's anthropometry and seat parameters on seating comfort. The results defining the preferred seat profile and optimal compressed seat-pan surface have previously been published (Wang et al., 2018a, 2018b). This paper reports the results on distribution of body-seat contact forces and potential relationships between contact forces and perceived discomfort.

\section{Materials and methods}

The present work is based on the same experiment as the one already presented in detail in the paper (Wang et al., 2018b), which focused on the analysis of seat geometry parameters. Data collection is summarized briefly below.

\subsection{Data collection}

Data were collected from thirty-six participants (18 males, 18 females), aged from 19 to 56. They were recruited based on their body mass index (BMI) (healthy $18.5-25 \mathrm{~kg} / \mathrm{m}^{2}$, obese $>30 \mathrm{~kg} / \mathrm{m}^{2}$ ) and stature (short, medium and tall). Three groups were formed by stature: $154-157$ $\mathrm{cm}, 162-166 \mathrm{~cm}$ and $170-175 \mathrm{~cm}$ for females; $168-171 \mathrm{~cm}, 176-180 \mathrm{~cm}$ and $185-190 \mathrm{~cm}$ for males. A total of 12 groups were formed based on sex, stature and BMI, with 3 individuals per group. The experimental protocol was approved by IFSTTAR (French Institute of Science and Technology for Transport, Development and Networks) ethics committee and informed prior consent was obtained for each participant.

A multi-adjustable experimental seat recently developed at IFSTTAR (Beurier et al, 2017) was used to simulate different seat configurations and to measure contact forces. The main adjustable parameters and the definition of the global (GCS) and local (LCS) coordinate systems are illustrated in Figure 1. The contact forces applied to the seat (not to the body) are expressed either in the GCS, with $\mathrm{x}$ horizontal and directed backward positively and $\mathrm{z}$ vertical and directed upward positively, or in the respective LCSs. For example, force components in $\mathrm{x}$ at the seat pan (SP) are denoted by Fx_SP_G and Fx_SP_L respectively in the global and local coordinate systems. The contact surfaces of the foot support (FS) and two armrests (AR) were oriented horizontally and their LCSs had the same orientation as the seat GCS. For the three back-support panels (lower, middle and upper supports respectively abbreviated as LS, MS and US), an LCS was defined for each panel via a rotary potentiometer that measured the panel's rotation. Axis $\mathrm{x}$ was tangential to the panel at the middle and $\mathrm{z}$ was perpendicular to $\mathrm{x}$ in the symmetry plane. The force components along $\mathrm{x}$ and $\mathrm{z}$ in their LCSs are denoted by Ft and Fn for the forces applied on the three back supports. The seat-pan surface was composed of a matrix of 52 cylinders, each with a freely rotatable circular flat head $60 \mathrm{~mm}$ in diameter. Each cylinder 
Post-print : WANG, Xuguang, CARDOSO, Michelle, BEURIER, Georges, 2018, Effects of seat parameters and sitters' anthropometric dimensions on seat profile and optimal compressed seat pan surface, Applied Ergonomics, 73, Elsevier, pp. 13-21, DOI: https://doi.org/10.1016/j.apergo.2018.05.015

was equipped with a tri-axial force sensor. The height of each cylinder was adjustable, with a maximum stroke length of $40 \mathrm{~mm}$. Pressure distribution on the seat-pan surface was controlled by lowering the cylinders' height to distribute cylinder contact axial forces as evenly as possible. The higher the cylinders, the more uniform the distribution of axial contact forces. Due to limited stroke length, it was not possible to generate a seat pan surface with a uniform distribution of the cylinder axial forces. For the seat pan and the cylinders, the corresponding LCSs were defined with x parallel to the non-deformed flat seat surface and directed backward positively, and $\mathrm{z}$ axial and directed upward positively.

\section{Figure 1}

Participants were instructed to sit in 12 different seat configurations with two sitting postures by varying the four independent variables:

- Seat-pan angle (A_SP) : $0^{\circ}, 5^{\circ}$ backward from the horizontal, Preferred

- Seat-back angle (A_SB): $10^{\circ}$ and $20^{\circ}$ backward from the vertical

- Initial cylinder height (CH): 20 and $40 \mathrm{~mm}$

- Posture (POSTURE): relaxed with use of head support (RLX), looking forward without use of head support (LFW)

For the economy class seats, one of most important specifications is that the range of backrest recline angle is quite limited due to small space between two rows of seats. The two backrest angles $\left(10^{\circ}\right.$ and $\left.20^{\circ}\right)$ were tested considering this specification. The test order of six A_SP/A_SB combinations was randomized. For each A_SP/A_SB combination, a 'reference configuration' with a flat seat-pan surface $(\mathrm{CH}=20 \mathrm{~mm})$ was used to determine seat-pan length, foot-support height and armrest position for each participant. The three backrest panels were positioned at specific anatomical points (occipital bone, T9 and L3). Their position in $\mathrm{x}$ was fixed at $135 \mathrm{~mm}$ in the seat-back LCS. The seat-pan length (X_SP_L, Figure 1) was adjusted to provide approximately $70 \mathrm{~mm}$ (hand width) between the popliteal (behind the knee) and the front of the seat pan. Participants were asked to keep their back in contact with the lower and middle supports. The foot support was adjusted (Z_FS, Figure 1) so that the knees were flexed at approximately 90 degrees. Participants were also asked to place a foam rectangle $100 \mathrm{~mm}$ thick between their knees to reduce postural variation. The armrests' height was self-positioned by subjects. After these seat adjustments, participants were instructed to step off the experimental seat to zero all the force sensors. Then, participants were asked to reposition themselves on the experimental seat and look forward without use of the upper (head) support. 
Post-print : WANG, Xuguang, CARDOSO, Michelle, BEURIER, Georges, 2018, Effects of seat parameters and sitters' anthropometric dimensions on seat profile and optimal compressed seat pan surface, Applied Ergonomics, 73, Elsevier, pp. 13-21, DOI: https://doi.org/10.1016/j.apergo.2018.05.015

Measurements were recorded at a rate of $20 \mathrm{~Hz}$ for 1.25 seconds. Finally, perceived seating discomfort was rated, using CP50, from 0 (imperceptible) to 50 (extremely strong) or more (Shen and Parsons, 1997). Though participants were allowed to take time to rate seating discomfort, sitting duration was less than two minutes for each test condition. The same procedure was repeated for the four $\mathrm{CH} /$ Posture conditions without modifying seat height and length. Moreover, the initially flat seat-pan surface was automatically deformed by lowering cylinder height to provide a more uniform distribution of compression forces among the 52 cylinders. Preferred seat-pan angle was self-selected by participants under the reference configuration and kept unchanged for the four other test conditions, with the same backrest angle. The conditions with $\mathrm{A} \_\mathrm{SP}=5^{\circ}$ and $\mathrm{A} \_\mathrm{SB}=20^{\circ}$ were tested three times, reaching a total number of 40 trials including the reference configurations.

\subsection{Data processing and analysis}

First, the medians of the measurements from each trial were calculated. Then, inconsistent trials due to either measurement or manipulation errors were eliminated. In particular, the sum of the external forces applied to the body had to equal zero. Therefore, an inclusion criterion was that the sum of external forces in the horizontal (X) and vertical $(\mathrm{Z})$ had to be smaller than 11 and $25 \mathrm{~N}$. This left 1372 out of 1440 (36 participants $\mathrm{x} 40$ conditions) trials.

All forces were expressed in \% of body weight (F/weight*100). To reduce individual effects on discomfort scores (CP50), the average score was calculated for each participant and the participant's score was centered relative to his/her average (CP50_C). Raw CP50 scores were also analyzed. Multifactor ANOVAs and multiple variable regressions were performed using STATGRAPHICS Centurion XVII. Effects of independent variables were considered 'significant' when $\mathrm{p}<0.05$. Three main anthropometric variables were proposed as predictors for regression equations of contact forces: stature, BMI and ratio of sitting height (from head to seat) to stature (RatioSH).

\section{Results}

As the reference configurations with a flat seat-pan surface were used for determining subject-specific seat parameters such as seat height and seat-pan length, the corresponding data were excluded from discomfort and contact force analysis. 
Post-print : WANG, Xuguang, CARDOSO, Michelle, BEURIER, Georges, 2018, Effects of seat parameters and sitters' anthropometric dimensions on seat profile and optimal compressed seat pan surface, Applied Ergonomics, 73, Elsevier, pp. 13-21, DOI: https://doi.org/10.1016/j.apergo.2018.05.015

\subsection{Perceived discomfort}

Multifactor analysis of variance of centered discomfort ratings CP50_C showed that all independent variables (A_SP, A_SB, CH, POSTURE) had a significant effect (Figure 2). Discomfort was reduced by increasing seat-pan angle (A_SP) and seat-back angle (A_SB). Lower discomfort was observed for relaxed posture (RLX) with use of head support than for looking forward (LFW) without use of head support. The configurations with higher initial cylinder height $(\mathrm{CH})$ had a lower discomfort score. A small but significant effect of interaction between A_SP and A_SB was also observed (Figure 3), showing that a more reclined seat pan lowered discomfort much more with a more reclined seat back. Self-selected seat-pan angles were on average respectively $5.9^{\circ}( \pm 3.1)$ and $6.7^{\circ}( \pm 3.0)$ for A_SB $=10^{\circ}$ and $20^{\circ}$ (Wang et al., $2018 \mathrm{c}$ ), quite close to $5^{\circ}$. No significant difference in discomfort was observed between A_SP $=5^{\circ}$ and A_SP $=\mathrm{PR}$ (Figure 2a).

Figure 2

Figure 3

To investigate the effect of participant group, non-centered CP50 ratings were analyzed; results are shown in Figure 4. Significantly higher discomfort was observed for groups FSO (Female Short Obese), FTH (Female Tall Healthy) and MTH (Male Tall Healthy). The two male obese groups (MSO and MTO) had the lowest discomfort rating. Considering gender, stature group and obesity as independent variables, significant effects of these factors and their interactions were also found.

Figure 4

\subsection{Contact forces}

The body is supported by different contact surfaces at foot support (FS), seat pan (SP), three back supports (LS, MS and US) and two armrests (AR). Table 1, Table 2 and Table 3 compare means of the $\mathrm{x}$ and $\mathrm{z}$ components of all contact forces for different test conditions in both global and local coordinate systems illustrated in Figure 1. The effects of anthropometric variables (Stature, RatioSH, BMI), seat parameters (A_SP, A_SB and $\mathrm{CH}$ ) and sitting posture (POSTURE) are summarized in regression equations in Table 4. For posture RLX with use of head support, on average, $67.4 \%, 19.2 \%, 3 \%, 6.9 \%, 0.4 \%$ and $4.5 \%$ of body weight were 
Post-print : WANG, Xuguang, CARDOSO, Michelle, BEURIER, Georges, 2018, Effects of seat parameters and sitters' anthropometric dimensions on seat profile and optimal compressed seat pan surface, Applied Ergonomics, 73, Elsevier, pp. 13-21, DOI: https://doi.org/10.1016/j.apergo.2018.05.015

supported respectively by seat pan, foot support, lower, middle and upper back supports and two armrests. The sum of these vertical force components should be $100 \%$ (body weight), but the actual value is $101.4 \%$ due to measurement errors. The horizontal force components were $13.4 \%,-1.8 \%, 3.9 \%, 10.6 \%, 0.8 \%,-0.3 \%$ of body weight respectively for seat pan, foot support, lower, middle and upper supports and two armrests. The sum of these horizontal forces should be zero, but there is an error of $-0.2 \%$. Forward horizontal forces were applied on the seat pan, foot support and armrests, and were balanced by the rearward forces on the three back supports.

The force applied on the head support was less than $1 \%$ of body weight and predominantly directed horizontally. The absence of head support use slightly affected the forces on the seat pan, lower and middle back supports and armrests, but had no effect on the foot support (see effect of POSTURE in Table 4).

A change in seat-pan angle (A_SP) significantly affected all contact forces except that on the head support (Table 4). A_SP had a strong effect on the shear force at the seat-pan surface (Fx_SP_L). On average, Fx_SP_L was $-11.4 \%$ for the horizontal seat pan A_SP $=0^{\circ}$, reducing to $-7.4 \%$ for A_SP $=5^{\circ}$. A more reclined seat pan slightly reduced the normal force (Fz_FS_G) and reduced the shear force (Fx_FS_G) on the foot support. It increased the force on the seat pan, lower and middle back supports.

A change in seat-back angle (A_SB) significantly affected all contact forces except that on the foot support (Table 4). A more reclined backrest led to higher contact forces at the three back supports and lower force at the seat pan, but had no effect on the force on the foot support. Compared to the configurations with $\mathrm{A}_{-} \mathrm{SB}=10^{\circ}$, a higher shear force at the seat-pan surface (Fx_SP_L) was observed for those with a more reclined backrest.

The parameters chosen to characterize the contact force distribution among the 52 cylinders were: the number of cylinders in contact with the buttock with a axial force component higher than $0.1 \%$ of body weight (nCy), the average cylinder axial force (Fzm), the peak cylinder axial force (Fzmax), as well as the corresponding force component in x (Fximax) and in the plane particular to the cylinder axis (Fxyimax) approximating the shear force under the ischial tuberosity. A higher initial cylinder height $(\mathrm{CH})$ was expected to induce more uniform distribution of the contact forces over the seat-pan surface. This is verified in Table 5 by a larger contact area with more cylinders in contact with the buttock (nCy), and lower average (Fzm) and peak cylinder axial force (Fzmax) in z. A higher initial cylinder height also led to a more deformed surface, which slightly affected all contact forces except the force on the lower (LS) and upper (US) supports. POSTURE had no effect on nCy, Fzm, Fzmax, Fximax, Fxyimax (Table 4). 
Post-print : WANG, Xuguang, CARDOSO, Michelle, BEURIER, Georges, 2018, Effects of seat parameters and sitters' anthropometric dimensions on seat profile and optimal compressed seat pan surface, Applied Ergonomics, 73, Elsevier, pp. 13-21, DOI: https://doi.org/10.1016/j.apergo.2018.05.015

Three anthropometric variables (Stature, RatioSH and BMI) affected almost all contact forces. BMI had a strong effect on contact force distribution on the cylinders, particularly on contact area (nCy) and peak cylinder force (Fzmax) (Table 4).

Table 1

Table 2

Table 3

Table 4

Table 5

\subsection{Relationship between discomfort and contact forces}

Pearson's correlation coefficients between two variables are summarized in Table 6. Very low correlations between either raw or centered CP50 ratings and contact forces were observed. The highest coefficient, -0.2, was found for CP50 and Fn_US, followed by the coefficient for CP50 and Fzmax (-0.135). Other contact forces relatively strongly correlated with either CP50 or CP50_C (with P-value $<0.001)$ include the normal components on the seat pan $\left(\mathrm{Fz}_{-} \mathrm{SP} \_\mathrm{L}\right)$, lower back support (Fn_LS) and armrests (Fz_AR_G), as well as the shear force on the armrests (Fx_AR_G).

Table 6

\section{Discussion}

The present work analyzed the contact forces between sitters and seat and their correlations with subjective discomfort perception. Contact forces normalized by body weight at all contact supports were provided for a large range of airplane economy class seat configurations. Regression models were obtained to predict contact forces as a function of anthropometric variables, seat-pan angle and backrest angle for two sitting postures.

As the contact forces are related by static equilibrium equations, they are not independent. The body weight will be supported more by back supports with a more reclined seat back leading to lower vertical force at the seat pan. As a change in seat-back angle (A_SB) only affects the upper body's posture without any effect on lower body position, A_SB is likely to affect the contact force at the armrests but not at the foot support. This can easily be verified from the regression equations listed in Table 4. However, a change in seat-pan angle (A_SP) 
Post-print : WANG, Xuguang, CARDOSO, Michelle, BEURIER, Georges, 2018, Effects of seat parameters and sitters' anthropometric dimensions on seat profile and optimal compressed seat pan surface, Applied Ergonomics, 73, Elsevier, pp. 13-21, DOI: https://doi.org/10.1016/j.apergo.2018.05.015

modifies the pelvis position, thus affecting both lower body position and lumbar curve (Keegan et al, 1953). The change in the pelvic position could help explain why A_SP affected nearly all contact forces except for the force applied on the head support (US). As body segment inertial parameters (e.g. mass, centre of mass, moment of inertia) depend on body size, therefore it is not surprising that Stature, RatioSH and BMI affected almost all contact forces (Table 4). Using a simplified articulated model, Goossens and Snijder (1995b) showed that horizontal forces are mainly generated by contact forces applied on the back support. This explains why the horizontal force components at the three back supports were all directed backwards and balanced by the forces applied on the seat pan, foot support and armrests. A principal component analysis (PCA)-based multi-variate regression was also performed, as explained in Wang et al. (2018a), to illustrate the effects of seat parameters (A_SP, A_SB) and anthropometric variables (Stature, RatioSH and BMI) on seat profile and contact forces.

Compared to body segment weight, the vertical force component for the armrests (Fz_AR_G, Table 1) was on average $4.5( \pm 1.8) \%$ of whole body weight, quite close to the total weight of two forearms and hands (4.6\% reported by Pheasant, 1986). The armrests were therefore used mainly to support the hands and forearms. On average, the vertical force component for the foot support (Fz_FS_G) was about $19.2( \pm 2.8) \%$ of whole body weight, much higher than the weight of two lower legs and feet (11.4\% reported by Pheasant, 1986). The foot support therefore also bore part of the thigh weight, reducing the force applied on the seat pan. Recall that the foot support height was adjusted so that the knee angle was approximatively $90^{\circ}$ : an overly high seat would have reduced the normal force on the foot support and increased the force on the seat pan.

Concerning the relationships between perceived discomfort and contact forces, only very weak correlations were found for some force components. Due to the subjective nature of discomfort perception, it is not surprising to find a lack in relationship between discomfort and objective measures. Nevertheless, relatively stronger correlations with perceived discomfort were found for peak cylinder axial force (Fzmax), global normal force applied on the seat pan (Fz_SP_L), normal forces on the lumbar (Fn_LS) and head (Fn_US) supports as well as normal (Fz_AR_G) and shear (Fx_AR_G) forces on the armrests. Our results are in agreement with De Looze et al. (2003), who concluded that pressure distribution at the backrest and/or seat pan was the objective measure with the clearest association with subjective ratings. Our findings also clearly support the general recommendation on seating comfort by Reed et al. (2000) that peak pressure should be reduced. Initially higher cylinders lowered peak cylinder axial force and led to a lower discomfort rating. However, no significant correlation between discomfort 
Post-print : WANG, Xuguang, CARDOSO, Michelle, BEURIER, Georges, 2018, Effects of seat parameters and sitters' anthropometric dimensions on seat profile and optimal compressed seat pan surface, Applied Ergonomics, 73, Elsevier, pp. 13-21, DOI: https://doi.org/10.1016/j.apergo.2018.05.015

and global shear force at the seat pan (Fx_SP_L) was found. Only a weak but significant correlation was found for the local shear force under the ischial tuberosity characterized by Fximax. Apart from the short females, there was generally lower perceived discomfort for the obese participants (Figure 4). This may be explained by a more uniform pressure distribution on the seat pan. A sitter with a higher BMI had a larger contact area (larger nCy), and lower peak (Fzmax) and mean (Fzm) pressure (Table 4).

Another common recommendation is to minimize shear force on the seat cushion by changing the cushion angle and/or contouring the cushion (Reed et al., 2000). Some researchers (Goossens et al., 1994; Zhang and Roberts, 1993) hypothesized that shear force at the seat pan surface is an important factor causing pressure sores and discomfort. One of our initial working hypotheses was that people prefer a seat-pan angle that minimizes the shear force at the seat pan for a given backrest angle. This was verified in Wang et al. (2018c) by comparing the shear forces of the conditions involving a self-selected seat-pan angle (A_SP=PR) with those using two imposed seat-pan angles $\left(\mathrm{A}_{-} \mathrm{SP}=0^{\circ}\right.$ and $5^{\circ}$ ) under the reference configurations (Table 7). Both A_SP and A_SB significantly affected shear force, which increased with A_SB and decreased with A_SP. As expected, the lowest shear force was observed for the conditions with self-selected seat-pan angles. Compared to A_SP $=0^{\circ}$ (a horizontal seat pan), the shear force on the seat pan (Fx_SP_L) was reduced from $8.56 \%$ to $4.61 \%$ and from $10.57 \%$ to $6.19 \%$ of body weight on average respectively for a seat-back angle of $10^{\circ}$ and $20^{\circ}$. This supports the hypothesis that a reduced shear force is preferred. Rasmussen et al. (2009) calculated optimum seat-pan and -back angles to minimize both muscle and contact forces. The preferred seat-pan angles observed in the present study, about $6^{\circ}$ and $7^{\circ}$ respectively for a seat-back angle of $10^{\circ}$ and $20^{\circ}$, were much less reclined (backward) than those predicted by Rasmussen et al., with a backrest-seat-pan angle of between $94^{\circ}$ and $103^{\circ}$. Keegan (1953) recommended a minimum angle of $105^{\circ}$ between seat pan and back (trunk-thigh angle) to preserve a good lumbar curvature (see also the review by Harrison et al., 2000). To fully remove shear force, a more reclined seat pan would be required with a smaller trunk-thigh angle, as already observed by Goossens and Snijders (1995). However this was not what participants wanted. Our results suggest that sitters preferred a seat-pan inclination that reduced shear force while maintaining a minimum trunk-thigh angle, as already suggested by Keagan (1953).

Table 7 
Post-print : WANG, Xuguang, CARDOSO, Michelle, BEURIER, Georges, 2018, Effects of seat parameters and sitters' anthropometric dimensions on seat profile and optimal compressed seat pan surface, Applied Ergonomics, 73, Elsevier, pp. 13-21, DOI: https://doi.org/10.1016/j.apergo.2018.05.015

The data of external contact forces could be useful when computational human models are used to estimate the difficult-to-measure internal loads, such as inter-disc pressure, muscle forces, or soft tissue deformation. From a recent review of finite element (FE) models for assessing sitting discomfort, Savonnet et al. (2018) concluded that existing models suffer from lack of validation and inability to define appropriate boundary conditions. Partial models only covering the buttocks and thighs require boundary conditions that cannot be adequately defined without knowing the full range of contact forces. Full-body models can use the knowledge of external contact forces to verify simulations. For the multibody musculoskeletal (MSK) models as the one developed by Rasmussen and colleagues from Anybody Research Group, Aalborg University (Rasmussen et al, 2009), the external loads on the body have to be known in order to compute internal forces such as joint moments and forces. When simulating a seated person, the external loads are the gravitational force and the forces at all contact surfaces, which are unknown a priori. Rasmussen at al. (2009) considered the contact forces as a specific muscle force to be optimized so as to minimize the muscle activity required to retain the posture. Like deformable FE models, multibody MSK models suffer from lack of validation. As an initial verification of the Anybody MSK model, Olesen et al. (2014) compared the predicted and measured contact forces at the footrest and seat pan for different seat-pan and -back angles. Correlation coefficients higher than 0.93 were obtained between measured and predicted reaction forces on the seat pan. However, the experimental set-up was very simplified: no arm and head rests were provided. Data were collected only from three male subjects whose body size came close to the 'seated human' model of the average-height male. It will be interesting to carry out further validation of MSK models based on the data collected from the present study.

We would like to point out the limitations of the present study. Firstly, the sample size of participants was too small to investigate gender, obesity and body-size effects especially on discomfort. Participants were selected by stature and weight to cover a large range of female and male sitters allowing a parametric study on contact forces. But due to subjective nature of discomfort rating implying large intra and inter-individual variability, clearly much larger sample size is required. Secondly, only two postures representing airplane TTL (Taxi Takeoff and Landing) and relaxing were studied. This is far from the large number of activities that an airplane passenger can do during an air travel (e.g. eating, reading, sleeping, working with a laptop, etc...). Thirdly, seat parameters were adjusted during a sitting duration less than 2 minutes, discomfort was rated without considering long-term sitting. Lastly, in addition to these limitations, measuring the shear force between seat and buttock is still an issue. The force 
Post-print : WANG, Xuguang, CARDOSO, Michelle, BEURIER, Georges, 2018, Effects of seat parameters and sitters' anthropometric dimensions on seat profile and optimal compressed seat pan surface, Applied Ergonomics, 73, Elsevier, pp. 13-21, DOI: https://doi.org/10.1016/j.apergo.2018.05.015

component perpendicular to the cylinder axis represents the shear force only when the seat-pan surface is flat. Once deformed, the rotatable head follows the body shape and the shear force needs to be estimated from the deformed contact surface. Moreover, as already mentioned in Beurier et al. (2017), no moment for a cylinder should be transmitted to its rotatable head. Yet due to rotational friction and the limited range of motion between the head and the rest of the cylinder, moment is unavoidable, leading to inaccurate tangential force component measurements. Only the force components in $\mathrm{x}$ or in the xy plane of the cylinder with the highest compression force were analyzed as its head probably had the smallest rotation.

\section{Conclusions}

The present study provides the contact forces between sitters and seat at all contact surfaces for a range of seating configurations generated using a configurable seat, based on 36 differently-sized males and females. Effects of sitters' anthropometry and seat parameters are summarized in the form of regression equations. Results show that small but not zero shear force is preferred for preserving a more open trunk-thigh angle when sitters can self-select seatpan angle. Initially perceived discomfort appears to be significantly correlated with normal force distribution on the seat-pan surface characterized by peak and mean normal forces in agreement with past studies (De Looze et al., 2003; Zemp et al., 2015). Significant relationships were also found with forces at the lumbar and head supports. Compared to the configurations without the use of head support, headrest use significantly lowered discomfort. For the lumbar support, it could be interesting in the future to study its effect on seating discomfort by testing different position in addition to the preferred lumbar support position. Due to small participant sample size, the findings regarding the effects of gender, stature and obesity on seating discomfort need to be further confirmed with more participants for each group. In addition to preferred seat profile parameters (Wang et al, 2018b), the present work provides quantitative guidelines on contact force requirement for improving seating comfort and contribute valuable sitting biomechanical data.

\section{Acknowledgement}

The work is partly supported by Direction Générale de l'Aviation Civile (project n²014 930818) in collaboration with Zodiac Seat France. 
Post-print : WANG, Xuguang, CARDOSO, Michelle, BEURIER, Georges, 2018, Effects of seat parameters and sitters' anthropometric dimensions on seat profile and optimal compressed seat pan surface, Applied Ergonomics, 73, Elsevier, pp. 13-21, DOI: https://doi.org/10.1016/j. apergo.2018.05.015

\section{References}

Beurier, G., Cardoso, M., and Wang, X., 2017. A new multi-adjustable experimental seat for investigating biomechanical factors of sitting discomfort. SAE Technical Paper 2017-011393, doi:10.4271/2017-01-1393. Warrendale, PA: SAE International

Bush, T.R. and Hubbard R. P., 2007. Support Force Measures of Midsized Men in Seated Positions. Journal of Biomechanical Engineering- 129 (1), 58-65. doi:10.1115/1.2401184

De Looze, M.P., Kuijt-Evers; L.F., van Dieen, J., 2003. Sitting comfort and discomfort and the relationships with objective measures. Ergonomics, 46, 985-97.

Goossens, R. H. M., Zegers, R., Dijke, G. A., Snijders, C. J., 1994. Influence of shear on skin oxygen tension. Clinical physiology, 14(1), 111-118

Goossens, R.H.M., Teeuw, R., Snijders, C.J., 1995a. Sensitivity for pressure difference on the ischial tuberosity, Ergonomics, 48:7, 895-902, DOI: 10.1080/00140130500123647

Goossens, R.H.M. and Snijders, C.J., 1995b. Design criteria for the reduction of shear forces in beds and seats. Journal of biomechanics, 28(2), 225-230.

Harrison, D. D., S. O. Harrison, A. C. Croft, D. E. Harrison, and S. J. Troyanovich. 2000. Sitting Biomechanics, Part II: Optimal Car Driver's Seat and Optimal Driver's Spinal Model. Journal of Manipulative and Physiological Therapeutics 23, no 1 (janvier 2000): 37-47. https://doi.org/10.1016/S0161-4754(00)90112-X.

Hiemstra-van Mastrigt, S., Groenesteijn, L., Vink, P. and Kuijt-Evers, L.F., 2017. Predicting Passenger Seat Comfort and Discomfort on the Basis of Human, Context and Seat Characteristics: A Literature Review. Ergonomics 60, no. 7 (July 3, 2017): 889-911. https://doi.org/10.1080/00140139.2016.1233356.

Hartung, J., Schlicht, T. and Bubb, H., 2004. Sensitivity of human pressure feelings while sitting. SAE Technical Paper 2004-01-2140, 2004, https://doi.org/10.4271/2004-01-2140. Warrendale, PA: SAE International

Jones, M., Park, J., Ebert-Hamilton, S., Kim, K. and Reed, M., 2017. Effects of Seat and Sitter Dimensions on Pressure Distribution in Automotive Seats. SAE Technical Paper 2017-011390, https://doi.org/10.4271/2017-01-1390, Warrendale, PA: SAE International

Mergl, C., Klendauer, M., Mangen, C., and Bubb, H., 2005. Predicting Long Term Riding Comfort in Cars by Contact Forces Between Human and Seat. SAE Technical Paper 200501-2690, 2005, https://doi.org/10.4271/2005-01-2690. Warrendale, PA: SAE International

Olesen, C.G., de Zee, M. and Rasmussen, J., 2014. Comparison between a computational seated human model and experimental verification data. Applied Bionics and Biomechanics 11 
Post-print : WANG, Xuguang, CARDOSO, Michelle, BEURIER, Georges, 2018, Effects of seat parameters and sitters' anthropometric dimensions on seat profile and optimal compressed seat pan surface, Applied Ergonomics, 73, Elsevier, pp. 13-21, DOI: https://doi.org/10.1016/j. apergo.2018.05.015

(2014) 175-183. DOI 10.3233/ABB-140105

Pheasant, S., 1986. Bodyspace: anthropometry, ergonomics and design. Taylor \& Francis.

Rasmussen, J., Torholm, S., de Zee, M., 2009. Computational analysis of the influence of seat pan inclination and friction on muscle activity and spinal joint forces. Int J Ind Ergon 39, $52-57$

Reed, M.P., Schneider, L.W., and Ricci, L.L., 1994. Survey of Auto Seat Design Recommendations for Improved Comfort. Technical Report UMTRI-94-6. University of Michigan Transportation Research Institute, Ann Arbor, MI. (Updated version in 2000, personal communication)

Savonnet, S. Wang, X. and Duprey, S., 2018. Finite element models of the thigh-buttock complex for assessing static sitting discomfort and pressure sore risk: a literature review, Computer Methods in Biomechanics and Biomedical Engineering, 21:4, 379-388, DOI: $10.1080 / 10255842.2018 .1466117$

Vink, P. and Lips, D., 2017. Sensitivity of the human back and buttocks: The missing link in comfort seat design. Applied Ergonomics, 58: 287-292. doi: 10.1016/j.apergo.2016.07.004

Wang, X., Beurier, G., 2018a. Determination of the optimal seat profile parameters for an airplane eco-class passenger seat. SAE Technical Paper 2018-01-1324, doi:10.4271/201801-1324. Warrendale, PA: SAE International

Wang X., Cardoso M. and Beurier G., 2018b. Effects of seat parameters and sitters' anthropometric dimensions on seat profile and optimal compressed seat pan surface. Applied Ergonomics, 73: 13-21.

Wang, X., Cardosso, M., Theodorakos, I., and Beurier, B., 2018c. Does Preferred Seat Pan Inclination Minimize Shear Force? In Proceedings of the 20th Congress of the International Ergonomics Association (IEA 2018), édité par Sebastiano Bagnara, Riccardo Tartaglia, Sara Albolino, Thomas Alexander, et Yushi Fujita, 290-95. Advances in Intelligent Systems and Computing. Springer International Publishing, 2019.

Zemp. R., Taylor, W.R., Lorenzetti, S., 2015. Are pressure measurements effective in the assessment of office chair comfort/discomfort? A review. Applied Ergonomics; 48:273-82.

Zhang, M., \& Roberts, V. C., 1993. The effect of shear forces externally applied to skin surface on underlying tissues. Journal of biomedical engineering, 15(6), 451-456 
Post-print : WANG, Xuguang, CARDOSO, Michelle, BEURIER, Georges, 2018, Effects of seat parameters and sitters' anthropometric dimensions on seat profile and optimal compressed seat pan surface, Applied Ergonomics, 73, Elsevier, pp. 13-21, DOI: https://doi.org/10.1016/j.apergo.2018.05.015

\section{Figures}

PRC: Reference point of the experimental seat

L: Local coordinate system

FS: Foot support

SP: Seat pan

Zsp

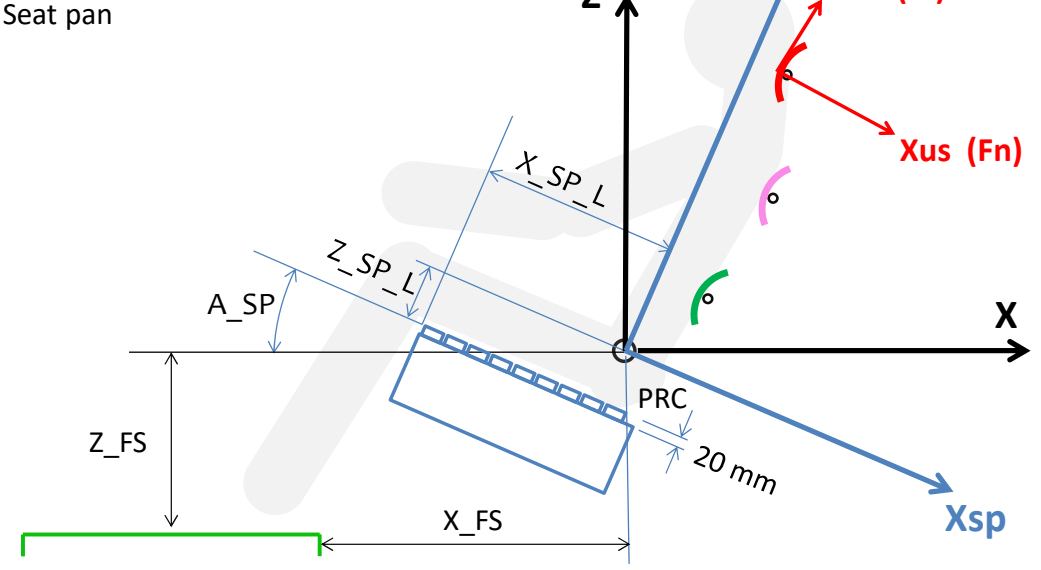

(a)

SB: Seat back

LS: Lower support

MS: Middle support

US: Upper support

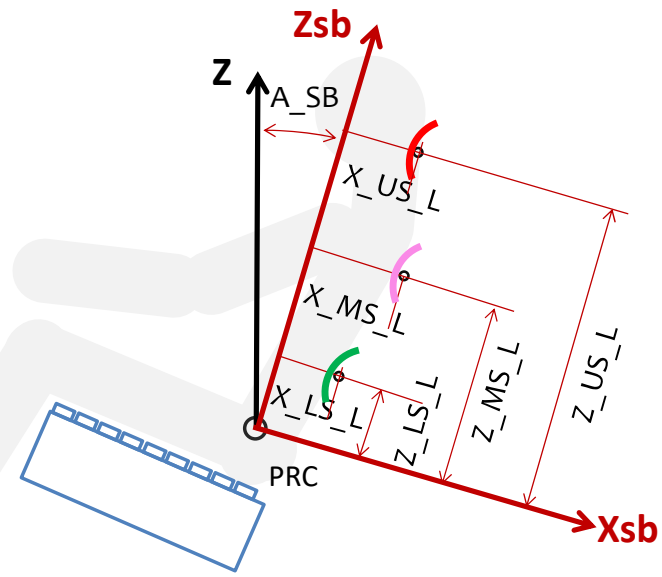

(b)

Figure 1. Definition of the adjustable seat parameters and different coordinate systems. The tangential and normal force components in the seat symmetry plane XZ are also illustrated for the upper support. 
Post-print : WANG, Xuguang, CARDOSO, Michelle, BEURIER, Georges, 2018, Effects of seat parameters and sitters' anthropometric dimensions on seat profile and optimal compressed seat pan surface, Applied Ergonomics, 73, Elsevier, pp. 13-21, DOI: https://doi.org/10.1016/j.apergo.2018.05.015

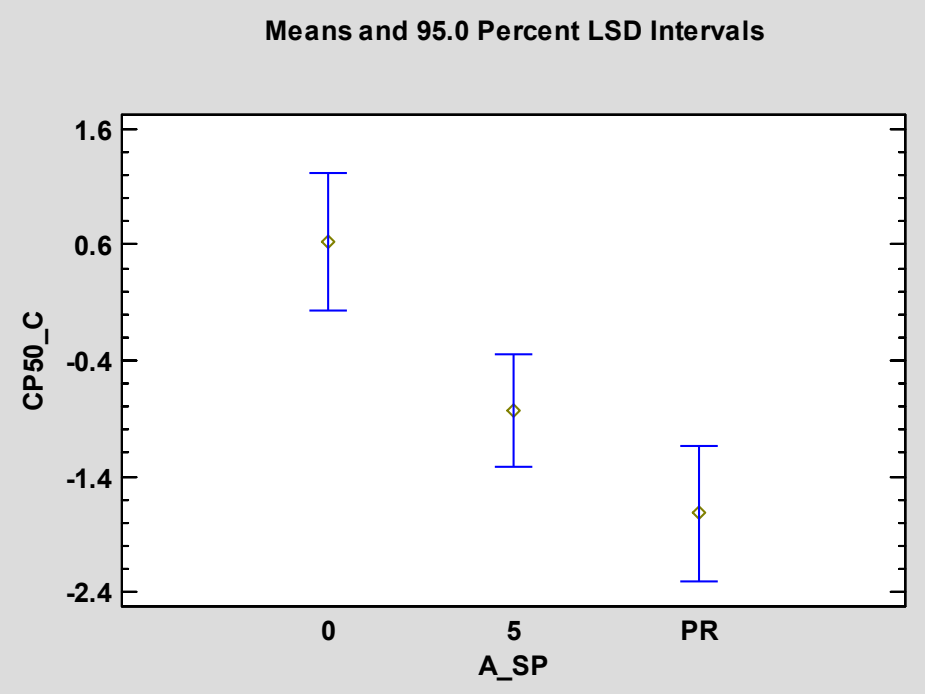

(a)

Means and 95.0 Percent LSD Intervals

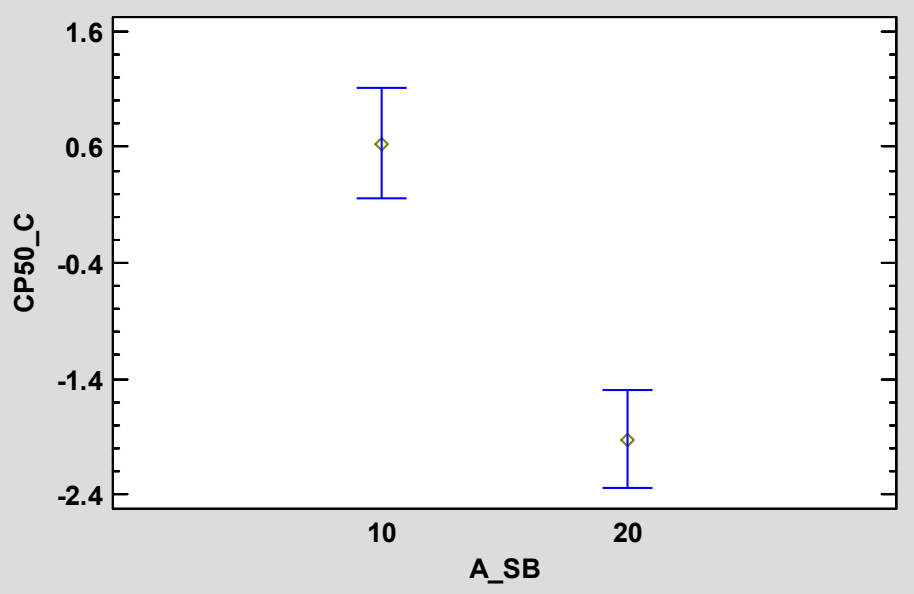

(b) 
Post-print : WANG, Xuguang, CARDOSO, Michelle, BEURIER, Georges, 2018, Effects of seat parameters and sitters' anthropometric dimensions on seat profile and optimal compressed seat pan surface, Applied Ergonomics, 73, Elsevier, pp. 13-21, DOI: https://doi.org/10.1016/j.apergo.2018.05.015

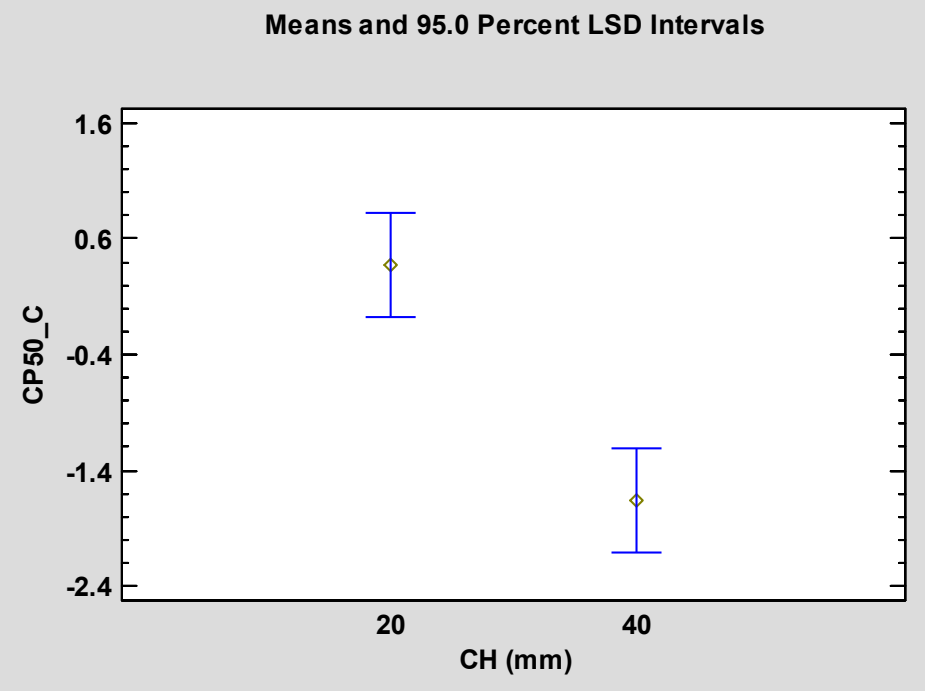

(c)

Means and 95.0 Percent LSD Intervals

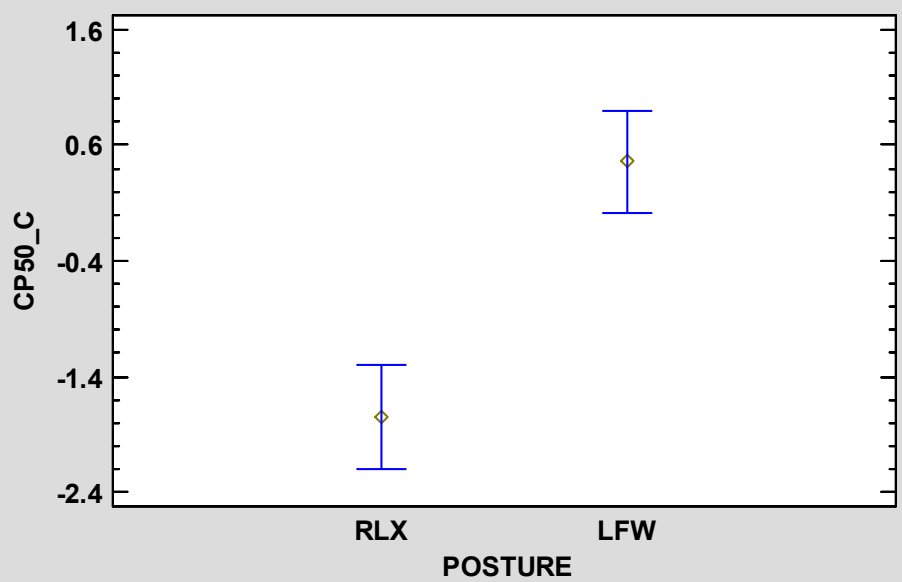

(d)

Figure 2. Main effect of the four seat independent variables on centered CP50 ratings: (a) seat-pan angle (A_SP), (b) seat-back angle (A_SB), (c) initial cylinder height (CH) and (d) Posture. Ratings were centered to each participant's mean score. Means and 95\% Fisher's least significant difference (LSD) intervals are plotted. 
Post-print : WANG, Xuguang, CARDOSO, Michelle, BEURIER, Georges, 2018, Effects of seat parameters and sitters' anthropometric dimensions on seat profile and optimal compressed seat pan surface, Applied Ergonomics, 73, Elsevier, pp. 13-21, DOI: https://doi.org/10.1016/j.apergo.2018.05.015

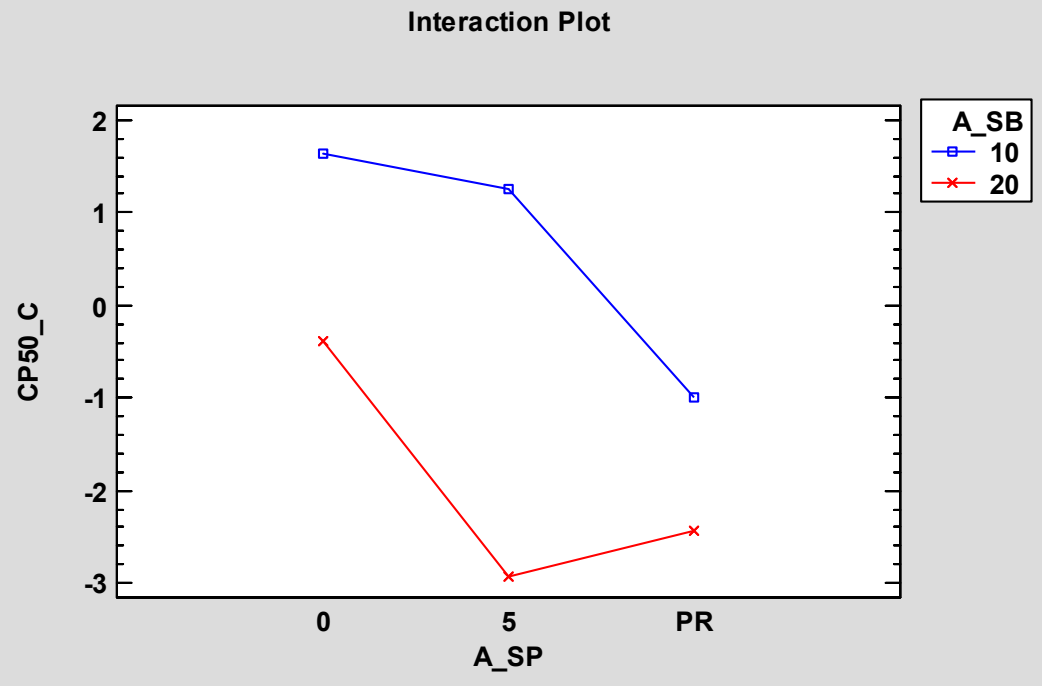

Figure 3. Effect of interaction between seat-pan angle (A_SP) and seat-back angle (A_SB) on centered CP50 discomfort ratings. Ratings were centered to each participant's mean score.

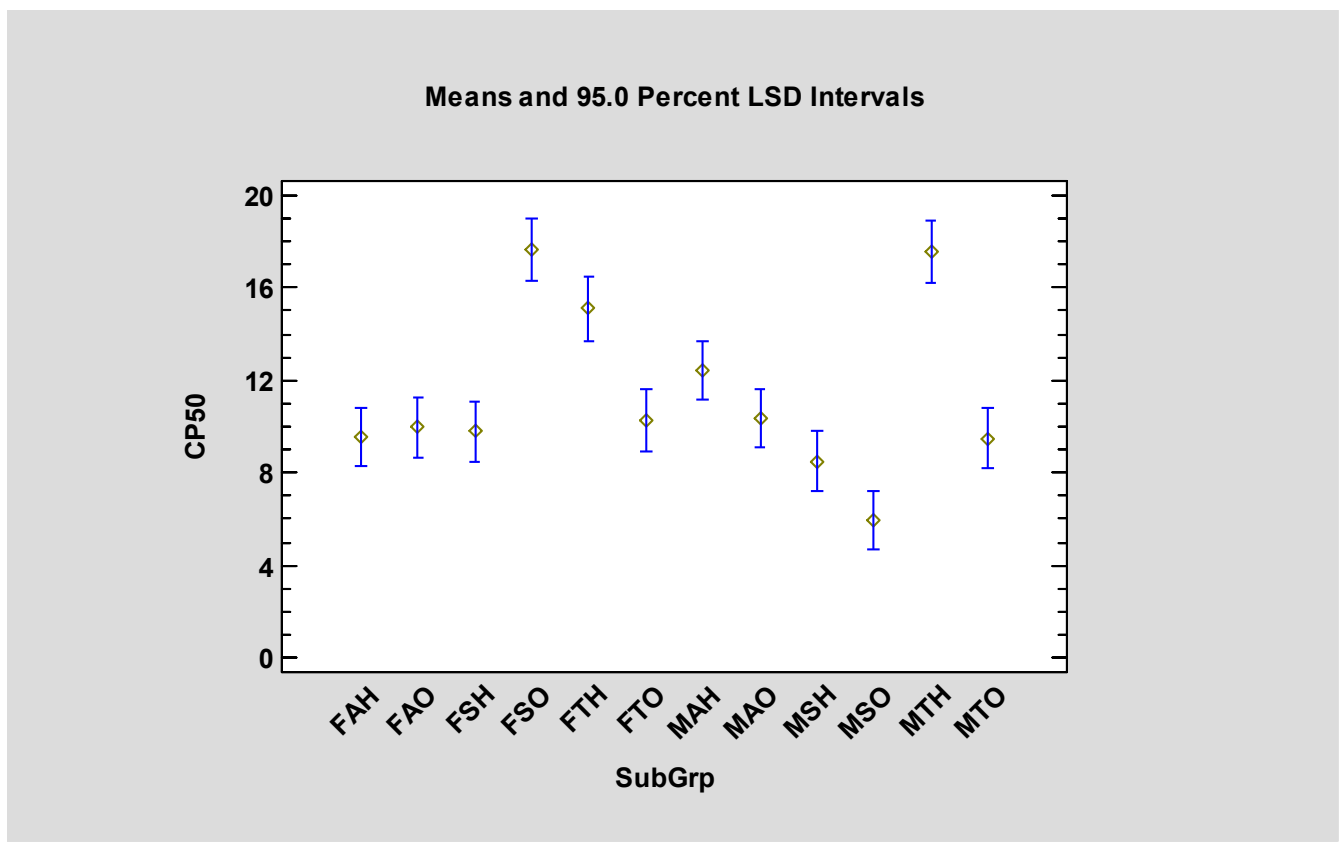

Figure 4. Means and 95\% least significant difference intervals of CP50 ratings for the 12 participant groups. F: Female, M: Male, A: Average height, S: Short, T: Tall; H: Healthy, O: Obese 
Post-print : WANG, Xuguang, CARDOSO, Michelle, BEURIER, Georges, 2018, Effects of seat parameters and sitters' anthropometric dimensions on seat profile and optimal compressed seat pan surface, Applied Ergonomics, 73, Elsevier, pp. 13-21, DOI: https://doi.org/10.1016/j.apergo.2018.05.015

\section{Tables}


Table 1. Mean values of contact forces applied to the seat in the vertical direction z at the foot rest (FS), seat pan (SP), three back supports (LS, MS and UP) and two armrests (AR) in the seat global coordinate system by seat configuration for two sitting postures RLX (using the headrest) and LFW (without using the headrest). Positive force component in $\mathrm{z}$ is directed upwards. Data from the reference configurations were excluded. Forces are in \% of body weight.

\begin{tabular}{|c|c|c|c|c|c|c|c|c|c|c|c|}
\hline \multirow[b]{2}{*}{ POSTURE } & \multicolumn{2}{|c|}{ Fz_SP_G } & \multicolumn{2}{|c|}{ Fz_FS_G } & \multicolumn{2}{|c|}{ Fz_LS_G } & \multicolumn{2}{|c|}{ Fz_MS_G } & \multirow{2}{*}{$\begin{array}{l}\text { Fz_US_G } \\
\text { RLX }\end{array}$} & \multicolumn{2}{|c|}{ Fz_AR_G } \\
\hline & RLX & LFW & RLX & LFW & RLX & LFW & RLX & LFW & & RLX & LFW \\
\hline A_SP $=0^{\circ}$ & -66.7 & -67.4 & -20.8 & -20.8 & -2.3 & -2.6 & -6.2 & -5.2 & -0.4 & -4.5 & -4.7 \\
\hline A_SB $=10^{\circ}$ & -68.4 & -69.3 & -20.9 & -20.8 & -1.9 & -2.0 & -5.0 & -4.0 & -0.3 & -4.4 & -4.7 \\
\hline $\mathrm{CH}=20$ & -67.2 & -68.0 & -22.4 & -22.3 & -1.8 & -2.0 & -4.7 & -3.7 & -0.4 & -4.5 & -4.8 \\
\hline $\mathrm{CH}=40$ & -69.5 & -70.5 & -19.5 & -19.4 & -1.9 & -2.0 & -5.2 & -4.3 & -0.3 & -4.4 & -4.5 \\
\hline A_SB $=20^{\circ}$ & -65.0 & -65.6 & -20.7 & -20.8 & -2.8 & -3.1 & -7.4 & -6.5 & -0.4 & -4.6 & -4.8 \\
\hline $\mathrm{CH}=20$ & -63.5 & -64.3 & -22.2 & -22.2 & -2.8 & -3.3 & -7.3 & -6.2 & -0.4 & -4.6 & -4.9 \\
\hline $\mathrm{CH}=40$ & -66.2 & -66.9 & -19.3 & -19.4 & -2.8 & -3.0 & -7.5 & -6.7 & -0.4 & -4.5 & -4.7 \\
\hline A_SP $=5^{\circ}$ & -67.3 & -68.4 & -18.8 & -18.7 & -2.8 & -3.2 & -7.3 & -6.2 & -0.5 & -4.6 & -4.7 \\
\hline A_SB $=10^{\circ}$ & -70.0 & -70.9 & -18.8 & -18.7 & -2.0 & -2.2 & -5.2 & -4.2 & -0.4 & -4.7 & -5.0 \\
\hline $\mathrm{CH}=20$ & -69.0 & -69.6 & -20.1 & -20.1 & -1.7 & -2.1 & -5.2 & -4.1 & -0.4 & -4.8 & -5.2 \\
\hline $\mathrm{CH}=40$ & -71.0 & -72.5 & -17.5 & -17.0 & -2.4 & -2.2 & -5.2 & -4.4 & -0.4 & -4.6 & -4.9 \\
\hline A_SB $=20^{\circ}$ & -66.4 & -67.5 & -18.8 & -18.6 & -3.1 & -3.6 & -8.0 & -6.9 & -0.5 & -4.5 & -4.6 \\
\hline $\mathrm{CH}=20$ & -65.2 & -66.2 & -20.3 & -20.0 & -2.9 & -3.6 & -7.8 & -6.6 & -0.5 & -4.6 & -4.8 \\
\hline $\mathrm{CH}=40$ & -67.6 & -68.9 & -17.4 & -17.2 & -3.3 & -3.5 & -8.2 & -7.2 & -0.5 & -4.4 & -4.4 \\
\hline A_SP=PR & -68.4 & -69.2 & -18.6 & -18.5 & -2.6 & -3.0 & -6.6 & -5.8 & -0.4 & -4.6 & -4.8 \\
\hline A_SB $=10^{\circ}$ & -70.5 & -71.1 & -18.7 & -18.4 & -2.1 & -2.3 & -4.9 & -4.2 & -0.3 & -4.6 & -5.0 \\
\hline $\mathrm{CH}=20$ & -69.0 & -70.0 & -20.1 & -19.8 & -2.0 & -2.2 & -5.0 & -4.0 & -0.3 & -4.9 & -5.2 \\
\hline $\mathrm{CH}=40$ & -72.0 & -72.2 & -17.2 & -17.2 & -2.3 & -2.5 & -4.9 & -4.4 & -0.3 & -4.3 & -4.9 \\
\hline A_SB $=20^{\circ}$ & -66.4 & -67.3 & -18.5 & -18.5 & -3.1 & -3.6 & -8.2 & -7.2 & -0.5 & -4.6 & -4.6 \\
\hline $\mathrm{CH}=20$ & -65.4 & -65.6 & -19.8 & -20.0 & -3.1 & -3.8 & -7.9 & -7.0 & -0.5 & -4.8 & -4.8 \\
\hline $\mathrm{CH}=40$ & -67.5 & -69.0 & -17.2 & -16.9 & -3.2 & -3.4 & -8.5 & -7.4 & -0.5 & -4.4 & -4.4 \\
\hline Total & -67.4 & -68.3 & -19.2 & -19.2 & -2.7 & -3.0 & -6.9 & -5.8 & -0.4 & -4.5 & -4.7 \\
\hline ( $\pm s t d)$ & \pm 4.3 & \pm 4.3 & \pm 2.8 & \pm 2.8 & \pm 1.6 & \pm 1.7 & \pm 2.9 & \pm 2.7 & \pm 0.4 & \pm 1.8 & \pm 2.6 \\
\hline
\end{tabular}


Table 2. Mean values of contact forces applied to the seat in the horizontal direction $x$ at the foot rest (FS), seat pan (SP), three back supports (LS, MS and UP) and two armrests (AR) in the seat global coordinate system by seat configuration for two sitting postures RLX (using the headrest) and LFW (without using the headrest). Positive force component in $x$ is directed backward. Data from the reference configurations were excluded. Forces are in \% of body weight.

\begin{tabular}{|c|c|c|c|c|c|c|c|c|c|c|c|}
\hline \multirow[b]{2}{*}{ POSTURE } & \multicolumn{2}{|c|}{ Fx_SP_G } & \multicolumn{2}{|c|}{ Fx_FS_G } & \multicolumn{2}{|c|}{ Fx_LS_G } & \multicolumn{2}{|c|}{ Fx_MS_G } & \multirow{2}{*}{$\begin{array}{l}\text { Fx_US_G } \\
\text { RLX }\end{array}$} & \multicolumn{2}{|c|}{ Fx_AR_G } \\
\hline & RLX & LFW & RLX & LFW & RLX & LFW & RLX & LFW & & RLX & LFW \\
\hline A_SP=0 $0^{\circ}$ & -11.9 & -11.9 & -1.7 & -1.7 & 3.3 & 4.1 & 9.6 & 9.7 & 0.8 & -0.3 & -0.4 \\
\hline A_SB $=10^{\circ}$ & -11.2 & -11.2 & -1.7 & -1.6 & 3.3 & 4.1 & 9.0 & 9.0 & 0.7 & -0.6 & -0.6 \\
\hline $\mathrm{CH}=20$ & -10.8 & -10.7 & -1.9 & -1.6 & 3.2 & 4.1 & 8.8 & 8.7 & 0.8 & -0.5 & -0.6 \\
\hline $\mathrm{CH}=40$ & -11.6 & -11.7 & -1.5 & -1.5 & 3.5 & 4.1 & 9.2 & 9.4 & 0.7 & -0.6 & -0.6 \\
\hline A_SB $=20^{\circ}$ & -12.6 & -12.6 & -1.8 & -1.8 & 3.2 & 4.1 & 10.3 & 10.5 & 0.9 & -0.1 & -0.2 \\
\hline $\mathrm{CH}=20$ & -12.1 & -12.3 & -1.9 & -1.8 & 3.0 & 4.3 & 10.1 & 10.0 & 0.9 & -0.1 & -0.2 \\
\hline $\mathrm{CH}=40$ & -13.0 & -13.0 & -1.6 & -1.7 & 3.3 & 3.9 & 10.5 & 11.0 & 0.9 & -0.1 & -0.2 \\
\hline A_SP=5 ${ }^{\circ}$ & -13.8 & -13.9 & -1.8 & -1.9 & 4.0 & 4.9 & 11.0 & 11.2 & 0.9 & -0.2 & -0.3 \\
\hline A_SB $=10^{\circ}$ & -12.4 & -12.7 & -1.8 & -1.8 & 3.7 & 4.8 & 10.2 & 10.1 & 0.7 & -0.6 & -0.7 \\
\hline $\mathrm{CH}=20$ & -12.0 & -12.4 & -2.0 & -1.8 & 3.5 & 4.7 & 10.1 & 10.0 & 0.8 & -0.6 & -0.7 \\
\hline $\mathrm{CH}=40$ & -12.9 & -13.0 & -1.7 & -1.7 & 4.0 & 4.9 & 10.3 & 10.3 & 0.7 & -0.5 & -0.6 \\
\hline A_SB $=20^{\circ}$ & -14.2 & -14.3 & -1.8 & -1.9 & 4.1 & 4.9 & 11.2 & 11.6 & 0.9 & -0.1 & -0.2 \\
\hline $\mathrm{CH}=20$ & -13.8 & -13.8 & -1.9 & -2.0 & 4.0 & 5.0 & 11.2 & 11.1 & 0.9 & -0.2 & -0.3 \\
\hline $\mathrm{CH}=40$ & -14.5 & -14.9 & -1.8 & -1.8 & 4.2 & 4.9 & 11.3 & 12.0 & 0.9 & 0.0 & -0.1 \\
\hline A_SP=PR & -14.1 & -14.2 & -1.8 & -1.9 & 4.5 & 5.3 & 10.7 & 11.0 & 0.8 & -0.3 & -0.4 \\
\hline A_SB $=10^{\circ}$ & -13.2 & -13.0 & -1.7 & -1.8 & 4.7 & 5.3 & 9.9 & 10.0 & 0.7 & -0.6 & -0.7 \\
\hline $\mathrm{CH}=20$ & -12.8 & -12.5 & -1.8 & -1.9 & 4.7 & 5.0 & 9.6 & 9.9 & 0.7 & -0.7 & -0.7 \\
\hline $\mathrm{CH}=40$ & -13.5 & -13.5 & -1.5 & -1.7 & 4.6 & 5.7 & 10.1 & 10.0 & 0.7 & -0.5 & -0.6 \\
\hline A_SB $=20^{\circ}$ & -15.0 & -15.3 & -1.8 & -1.9 & 4.3 & 5.3 & 11.6 & 12.0 & 0.9 & -0.1 & -0.1 \\
\hline $\mathrm{CH}=20$ & -14.8 & -15.3 & -1.9 & -2.0 & 4.6 & 5.7 & 11.3 & 11.7 & 0.9 & -0.2 & -0.2 \\
\hline $\mathrm{CH}=40$ & -15.1 & -15.4 & -1.8 & -1.9 & 4.1 & 4.9 & 11.9 & 12.4 & 0.8 & 0.0 & -0.1 \\
\hline Total & -13.4 & -13.5 & -1.8 & -1.8 & 3.9 & 4.8 & 10.6 & 10.8 & 0.8 & -0.3 & -0.4 \\
\hline ( $\pm s t d)$ & \pm 2.6 & \pm 2.7 & \pm 0.9 & \pm 0.8 & \pm 2.8 & \pm 3 & \pm 2.5 & \pm 2.8 & \pm 0.5 & \pm 0.7 & \pm 0.6 \\
\hline
\end{tabular}


Table 3. Mean values of contact forces applied to the seat at the seat pan (SP) and at three back supports (LS, MS and UP) in the respective local coordinate systems by seat configuration for two sitting postures RLX (using the headrest) and LFW (without using the headrest). Data from the reference configurations were excluded. Forces are in \% of body weight.

\begin{tabular}{|c|c|c|c|c|c|c|c|c|c|c|c|c|c|c|}
\hline \multirow[b]{2}{*}{ POSTURE } & \multicolumn{2}{|c|}{ Fz_SP_L } & \multicolumn{2}{|c|}{ Fn_LS } & \multicolumn{2}{|c|}{ Fn_MS } & \multirow{2}{*}{$\begin{array}{l}\text { Fn_US } \\
\text { RLX }\end{array}$} & \multicolumn{2}{|c|}{ Fx_SP_L } & \multicolumn{2}{|c|}{ Ft_LS } & \multicolumn{2}{|c|}{ Ft_MS } & \multirow{2}{*}{$\begin{array}{l}\text { Ft_US } \\
\text { RLX }\end{array}$} \\
\hline & RLX & LFW & RLX & LFW & RLX & LFW & & RLX & LFW & RLX & LFW & RLX & LFW & \\
\hline A_SP $=0^{\circ}$ & -66.8 & -67.5 & 3.7 & 4.6 & 11.4 & 11.0 & 0.9 & -11.4 & -11.4 & -1.4 & -1.4 & -1.7 & -1.5 & 0.0 \\
\hline A_SB $=10^{\circ}$ & -68.5 & -69.3 & 3.6 & 4.3 & 10.2 & 9.8 & 0.9 & -10.7 & -10.7 & -1.1 & -1.2 & -1.6 & -1.3 & 0.0 \\
\hline $\mathrm{CH}=20$ & -67.3 & -68.1 & 3.5 & 4.3 & 9.9 & 9.4 & 0.9 & -10.3 & -10.3 & -1.1 & -1.2 & -1.4 & -1.2 & 0.0 \\
\hline $\mathrm{CH}=40$ & -69.6 & -70.6 & 3.7 & 4.4 & 10.5 & 10.2 & 0.8 & -11.1 & -11.2 & -1.1 & -1.1 & -1.8 & -1.4 & 0.0 \\
\hline A_SB $=20^{\circ}$ & -65.1 & -65.7 & 3.8 & 4.8 & 12.7 & 12.3 & 1.0 & -12.1 & -12.2 & -1.6 & -1.7 & -1.9 & -1.7 & 0.0 \\
\hline $\mathrm{CH}=20$ & -63.6 & -64.4 & 3.7 & 5.0 & 12.4 & 11.7 & 1.0 & -11.6 & -11.8 & -1.7 & -1.8 & -1.9 & -1.7 & 0.0 \\
\hline $\mathrm{CH}=40$ & -66.3 & -67.0 & 4.0 & 4.6 & 12.9 & 12.9 & 1.0 & -12.6 & -12.5 & -1.6 & -1.5 & -1.8 & -1.8 & 0.0 \\
\hline A_SP $=5^{\circ}$ & -68.3 & -69.4 & 4.6 & 5.6 & 13.2 & 12.8 & 1.0 & -7.4 & -7.4 & -1.4 & -1.6 & -1.8 & -1.7 & 0.0 \\
\hline A_SB $=10^{\circ}$ & -70.8 & -71.8 & 4.1 & 5.1 & 11.4 & 11.0 & 0.9 & -5.8 & -6.0 & -1.1 & -1.0 & -1.6 & -1.5 & 0.0 \\
\hline $\mathrm{CH}=20$ & -69.8 & -70.4 & 3.8 & 5.0 & 11.3 & 10.8 & 0.9 & -5.4 & -5.9 & -0.9 & -1.1 & -1.6 & -1.4 & 0.0 \\
\hline $\mathrm{CH}=40$ & -71.9 & -73.4 & 4.4 & 5.2 & 11.5 & 11.2 & 0.8 & -6.2 & -6.2 & -1.4 & -0.9 & -1.5 & -1.5 & 0.0 \\
\hline A_SB $=20^{\circ}$ & -67.4 & -68.6 & 4.8 & 5.8 & 13.7 & 13.4 & 1.0 & -7.9 & -7.9 & -1.6 & -1.8 & -1.9 & -1.7 & 0.0 \\
\hline $\mathrm{CH}=20$ & -66.2 & -67.2 & 4.6 & 5.8 & 13.6 & 12.9 & 1.1 & -7.7 & -7.5 & -1.5 & -1.9 & -1.8 & -1.7 & 0.0 \\
\hline $\mathrm{CH}=40$ & -68.6 & -70.0 & 5.0 & 5.8 & 13.9 & 13.9 & 1.0 & -8.2 & -8.3 & -1.6 & -1.6 & -2.0 & -1.8 & 0.0 \\
\hline A_SP=PR & -69.5 & -70.3 & 5.0 & 5.9 & 12.6 & 12.5 & 0.9 & -6.5 & -6.6 & -1.3 & -1.4 & -1.8 & -1.6 & 0.0 \\
\hline A_SB $=10^{\circ}$ & -71.4 & -72.1 & 4.9 & 5.7 & 10.9 & 10.8 & 0.8 & -5.8 & -5.7 & -1.1 & -1.1 & -1.7 & -1.5 & 0.0 \\
\hline $\mathrm{CH}=20$ & -69.9 & -70.9 & 5.0 & 5.3 & 10.7 & 10.6 & 0.8 & -5.7 & -5.5 & -0.9 & -1.0 & -1.9 & -1.5 & 0.0 \\
\hline $\mathrm{CH}=40$ & -73.0 & -73.2 & 4.9 & 6.0 & 11.2 & 10.9 & 0.8 & -5.9 & -5.9 & -1.2 & -1.2 & -1.5 & -1.6 & 0.0 \\
\hline A_SB $=20^{\circ}$ & -67.7 & -68.6 & 5.1 & 6.2 & 14.1 & 14.1 & 1.0 & -7.1 & -7.4 & -1.5 & -1.6 & -1.9 & -1.7 & 0.0 \\
\hline $\mathrm{CH}=20$ & -66.6 & -66.9 & 5.3 & 6.6 & 13.7 & 13.7 & 1.1 & -7.1 & -7.5 & -1.5 & -1.8 & -1.8 & -1.6 & 0.0 \\
\hline $\mathrm{CH}=40$ & -68.8 & -70.3 & 4.9 & 5.8 & 14.6 & 14.4 & 1.0 & -7.1 & -7.2 & -1.6 & -1.5 & -2.0 & -1.8 & 0.0 \\
\hline Total & -68.2 & -69.1 & 4.5 & 5.4 & 12.6 & 12.3 & 1.0 & -8.1 & -8.2 & -1.4 & -1.5 & -1.8 & -1.6 & 0.0 \\
\hline ( \pm std) & \pm 4.3 & \pm 4.3 & \pm 3 & \pm 3.3 & \pm 3.3 & $3.4 \pm$ & \pm 0.5 & \pm 3.3 & \pm 3.2 & \pm 1.2 & \pm 1.2 & \pm 1.2 & \pm 1 & \pm 0.1 \\
\hline
\end{tabular}


Post-print : WANG, Xuguang, CARDOSO, Michelle, BEURIER, Georges, 2018, Effects of seat parameters and sitters' anthropometric dimensions on seat profile and optimal compressed seat pan surface, Applied Ergonomics, 73, Elsevier, pp. 13-21, DOI: https://doi.org/10.1016/j.apergo.2018.05.015

Table 4. Regression equations of the contact forces applied to the seat at the foot rest (FS), seat pan (SP), three back supports (LS, MS and UP) and two armrests (AR) in the seat global coordinate system. Positive force components in $\mathrm{x}$ and $\mathrm{z}$ are directed respectively horizontally backward and vertically upwards. Regressions equations of the distribution of cylinders' contact forces are also listed: number of compressed cylinders (nCy), average cylinder force along its axis Fzm, peak cylinder axial force Fzmax as well as the corresponding force component in $x$ (Fximax) and in the plane particular to the cylinder axis (Fxyimax). Data from the reference configurations were excluded. Forces are in \% of body weight.

\begin{tabular}{|c|c|c|c|c|c|c|c|c|c|c|}
\hline Variable & Constant & POSTURE* & $\begin{array}{l}\mathrm{CH} \\
(\mathrm{mm})\end{array}$ & $\begin{array}{l}\text { A_SP } \\
\left(^{\circ}\right)\end{array}$ & $\begin{array}{l}\text { A_SB } \\
\left({ }^{\circ}\right)\end{array}$ & $\begin{array}{l}\text { Stature } \\
(\mathrm{mm})\end{array}$ & $\begin{array}{l}\text { RatioSH } \\
\text { (x100) }\end{array}$ & $\begin{array}{l}\text { BMI } \\
\left(\mathrm{Kg} / \mathrm{m}^{2}\right)\end{array}$ & Adjusted $\mathrm{R}^{2}$ & MSE \\
\hline Fz_SP_G & -82.9 & 0.18 & -0.128 & -0.254 & 0.373 & 0.0093 & - & -0.074 & 0.340 & 12.2 \\
\hline Fx_SP_G & 30.0 & - & -0.037 & -0.382 & -0.154 & -0.0052 & -0.586 & 0.046 & 0.384 & 4.3 \\
\hline Fz_FS_G & -35.6 & - & 0.141 & 0.372 & - & -0.0029 & 0.252 & 0.088 & 0.455 & 4.3 \\
\hline Fx_FS_G & 3.5 & - & 0.009 & -0.026 & - & - & -0.115 & 0.018 & 0.06 & 0.7 \\
\hline Fz_LS_G & -11.1 & 0.17 & - & -0.08 & -0.116 & - & 0.201 & - & 0.152 & 2.5 \\
\hline Fx_LS_G & 27.8 & -0.44 & - & 0.242 & - & -0.0021 & -0.368 & -0.06 & 0.102 & 7.7 \\
\hline Fz_MS_G & 32.6 & -0.50 & -0.020 & -0.100 & - & -0.0033 & -0.589 & -0.058 & 0.099 & 7.4 \\
\hline Fx_MS_G & -62.5 & - & 0.023 & 0.178 & 0.147 & 0.011 & 0.971 & - & 0.352 & 4.6 \\
\hline Fz_US_G** & -1.1 & & & - & -0.013 & 0.0005 & - & - & 0.040 & 0.1 \\
\hline Fx_US_G** & 0.8 & & & - & 0.016 & & & -0.007 & 0.034 & 0.2 \\
\hline Fz_AR_G & -9.7 & - & 0.016 & -0.053 & 0.023 & -0.0046 & 0.201 & 0.068 & 0.204 & 2.7 \\
\hline Fx_AR_G & -6.2 & 0.04 & 0.005 & - & -0.048 & -0.0011 & - & 0.129 & 0.234 & 0.3 \\
\hline $\mathrm{nCy}$ & 44.4 & - & 0.385 & 0.296 & 0.056 & 0.0081 & -0.918 & 0.543 & 0.765 & 9.4 \\
\hline Fzm & -2.15 & - & 0.015 & 0.006 & 0.011 & 0.0006 & -0.040 & 0.024 & 0.695 & 0.03 \\
\hline Fzmax & -15.9 & - & 0.070 & 0.051 & 0.029 & 0.0021 & - & 0.172 & 0.637 & 1.04 \\
\hline Fximax & 0.35 & - & 0.006 & 0.030 & -0.020 & -0.0006 & - & 0.015 & 0.052 & 0.52 \\
\hline Fxyimax & 3.61 & - & -0.006 & -0.013 & - & -0.0008 & - & 0.043 & 0.256 & 0.25 \\
\hline
\end{tabular}

*Posture=1 for RLX, Posture =-1 for LFW. ${ }^{*}$ Only the data for RLX were used. 
Table 5. Number of compressed cylinders (nCy), mean (Fzm) and maximum (Fzmax) force component applied to a cylinder along its axis by seat configuration for two initial cylinder heights $(\mathrm{CH}=20$ and $40 \mathrm{~mm})$. Fximax and Fxyimax are the force components in $\mathrm{x}$ and in the xy of the cylinder's local reference system, corresponding to the cylinder of maximum compression. A cylinder was compressed when its axial force was greater than $0.1 \%$ of body weight. Data from the reference configurations were excluded. Forces are in $\%$ of body weight.

\begin{tabular}{|c|c|c|c|c|c|c|c|c|c|c|c|c|c|c|c|}
\hline \multirow[b]{2}{*}{$\mathrm{CH}(\mathrm{mm})$} & \multicolumn{2}{|l|}{$\mathrm{nCy}$} & \multicolumn{3}{|c|}{ Fzm } & \multicolumn{3}{|c|}{ Fzmax } & \multicolumn{3}{|c|}{ Fximax } & \multicolumn{3}{|c|}{ Fxyimax } & \multirow[b]{2}{*}{ Total } \\
\hline & 20 & 40 & Total & 20 & 40 & Total & 20 & 40 & Total & 20 & 40 & Total & 20 & 40 & \\
\hline A_SP $=0^{\circ}$ & 33.1 & 42.0 & 37.6 & -2 & -1.6 & -1.8 & -5.6 & -4.2 & -4.9 & -0.47 & -0.26 & -0.36 & 0.95 & 0.84 & 0.89 \\
\hline A_SB $=10^{\circ}$ & 33.4 & 41.7 & 37.6 & -2.1 & -1.7 & -1.9 & -5.7 & -4.3 & -5 & -0.43 & -0.16 & -0.30 & 0.94 & 0.86 & 0.90 \\
\hline A_SB $=20^{\circ}$ & 32.8 & 42.3 & 37.7 & -2 & -1.6 & -1.8 & -5.5 & -4.1 & -4.8 & -0.51 & -0.36 & -0.43 & 0.96 & 0.82 & 0.89 \\
\hline A_SP $=5^{\circ}$ & 36.1 & 43.5 & 39.7 & -1.9 & -1.6 & -1.8 & -5.3 & -3.9 & -4.6 & -0.25 & -0.18 & -0.22 & 0.90 & 0.71 & 0.81 \\
\hline A_SB $=10^{\circ}$ & 36.1 & 42.7 & 39.3 & -2 & -1.7 & -1.9 & -5.4 & -4.2 & -4.9 & 0.04 & -0.06 & -0.01 & 0.85 & 0.77 & 0.81 \\
\hline A_SB $=20^{\circ}$ & 36.1 & 43.7 & 39.9 & -1.9 & -1.6 & -1.7 & -5.3 & -3.8 & -4.5 & -0.36 & -0.21 & -0.29 & 0.92 & 0.70 & 0.81 \\
\hline A_SP=PR & 36.1 & 43.4 & 39.8 & -1.9 & -1.7 & -1.8 & -5.4 & -3.9 & -4.7 & -0.20 & -0.13 & -0.16 & 0.82 & 0.81 & 0.82 \\
\hline A_SB $=10^{\circ}$ & 35.8 & 43.2 & 39.5 & -2 & -1.7 & -1.9 & -5.5 & -4.1 & -4.8 & -0.10 & -0.07 & -0.08 & 0.80 & 0.84 & 0.82 \\
\hline A_SB $=20^{\circ}$ & 36.5 & 43.6 & 40.0 & -1.9 & -1.6 & -1.7 & -5.3 & -3.8 & -4.5 & -0.31 & -0.18 & -0.24 & 0.87 & 0.78 & 0.82 \\
\hline Total & 35.4 & 43.1 & 39.2 & -1.9 & -1.6 & -1.8 & -5.4 & -4.0 & -4.7 & -0.29 & -0.19 & -0.24 & 0.89 & 0.77 & 0.83 \\
\hline \pm SD & \pm 5.6 & \pm 4.3 & \pm 6.3 & \pm 0.3 & \pm 0.2 & $0.3 \pm$ & \pm 1.7 & \pm 1.3 & \pm 1.7 & \pm 0.82 & \pm 0.64 & \pm 0.74 & \pm 0.62 & \pm 0.53 & \pm 0.56 \\
\hline
\end{tabular}


Post-print : WANG, Xuguang, CARDOSO, Michelle, BEURIER, Georges, 2018, Effects of seat parameters and sitters' anthropometric dimensions on seat profile and optimal compressed seat pan surface, Applied Ergonomics, 73, Elsevier, pp. 13-21, DOI: https://doi.org/10.1016/j.apergo.2018.05.015

Table 6. Pearson's correlation coefficients between discomfort rating (CP50 and CP50_C) and contact forces. Data from the reference configurations were excluded.

\begin{tabular}{|c|c|c|c|c|c|c|c|c|c|c|c|c|c|c|c|c|c|c|}
\hline & CP50 & CP50_C & Fzmax & Fzm & Fximax & Fxyimax & Fx_SP_L & Fz_SP_L & Ft_LS & Fn_LS & Ft_MS & Fn_MS & Ft_US & Fn_US & Fx_FS_G & Fz_FS_G & Fx_AR_G & Fz_AR_G \\
\hline CP50 & & $0.792^{\mathrm{a}}$ & $-0.135^{a}$ & $-0.082^{b}$ & 0.019 & 0.045 & 0.036 & $-0.107^{a}$ & $0.096^{b}$ & $-0.108^{a}$ & 0.053 & -0.047 & -0.054 & $-0.200^{a}$ & -0.038 & $-0.074^{c}$ & 0.044 & $0.154^{a}$ \\
\hline CP50_C & $0.792^{\mathrm{a}}$ & & $-0.087^{b}$ & $-0.098^{b}$ & $0.062^{c}$ & -0.012 & 0.045 & -0.027 & $0.078^{c}$ & $-0.074^{c}$ & 0.027 & $-0.089^{b}$ & -0.046 & $-0.189^{a}$ & -0.027 & $-0.099^{b}$ & $-0.138^{a}$ & -0.027 \\
\hline
\end{tabular}

${ }^{\mathrm{a} P}<0.001,{ }^{\mathrm{b}} 0.001 \leq \mathrm{P}<0.01,{ }^{\mathrm{c}} 0.01 \leq \mathrm{P}<0.05$

Table 7. Means and standard deviations of the normalized shear force (Fx_SP_L) applied at the seat-pan surface when varying both seat-pan angle (A_SP) and seat-back angle (A_SB). PR is self-selected. Forces are in percentage of body weight. A negative force means the shear force applied on the seat is directed forward. Only data from the reference configurations were used.

\begin{tabular}{|c|c|c|c|c|c|c|}
\hline \multirow[b]{2}{*}{ A_SP } & \multicolumn{2}{|c|}{ A_SB $=10^{\circ}$} & \multicolumn{2}{|c|}{ A_SB $=20^{\circ}$} & \multicolumn{2}{|l|}{ Total } \\
\hline & Mean & $\mathrm{SD}$ & Mean & SD & Mean & $\mathrm{SD}$ \\
\hline $0^{\circ}$ & -8.56 & 1.78 & -10.57 & 1.79 & -9.58 & 2.05 \\
\hline $5^{\circ}$ & -4.73 & 2.17 & -6.92 & 1.93 & -6.38 & 2.20 \\
\hline PR & -4.61 & 2.97 & -6.19 & 3.01 & -5.42 & 3.07 \\
\hline Total & -5.97 & 2.98 & -7.51 & 2.67 & $-6.944^{\mathrm{A} \_S B^{* * *}, \mathrm{~A} \_\mathrm{SP} * * *}$ & 2.88 \\
\hline
\end{tabular}

$* \mathrm{P}<0.05,{ }^{* *} \mathrm{P}<0.01, * * * \mathrm{P}<0.001$ 